\title{
Aproximación a la organización bibliotecaria española en el siglo X VIII
}

\author{
AMPARO GaRCía CUADRADO \\ D epartamento de Información y D ocumentación. \\ Universidad de Murcia, Campus de Espinardo s/ n 30071 \\ Murcia. España. Tel. 34.68 .307100 ext. 2404 \\ Email:ampagar@fcu.um.es
}

\begin{abstract}
RESUMEN
El ideal ilustrado de felicidad pública, progreso y utilidad es asumido por las élites ilustradas españolas especialmente a lo largo de la segunda mitad del siglo XVIII. Este empeño por sacar al país de su atraso secular va a quedar patente en la adopción de una serie de medidas y normas legales en el campo educativo, científico y cultural. Pero la reforma de la enseñanza y la creación de Academias y Sociedades, exigía también, como base estructural, la apertura de bibliotecas públicas. A través de ellas se pretendía poner al alcance de todos aquellos instrumentos esenciales para el estudio y la lectura.

El análisis de las normas legales emanadas de la Corona, desde la fundación de la Real Biblioteca con la llegada de la dinastía borbónica, hasta la reorganización y formación de nuevas bibliotecas a partir de los fondos librarios dejados por los jesuitas españoles tras su expulsión en 1767, son un claro exponente de una organización bibliotecaria que pretendía hacer frente a una necesidad social percibida por la minoría dirigente.
\end{abstract}

\footnotetext{
ABST RACT

The illustrated ideal of public happiness, progress and usefulness is assumed by the Spanish illustrated élite, especially throughout the second half of the 18th century. This determination to take the country out of its secular backward state is going to be obvious in the adoption of a series of measures and normal regulations in the educational, scientific and cultural fields. But the education reform and the creation of Academies and Societies demanded also, as a structural base, the opening of public libraries. Through them it was intended to put at everybody's hand all those essential instruments for studying and reading. The analysis of the legal norms issued from the Crown, from the foundation of the Royal Library with the arrival of the Bourbon dynasty, to the re-organisation and formation of new libraries starting with the book stock left by Spanish Jesuits after their expulsion in 1767, are a clear exponent of a library organisation which tried to face a social need perceived by the governing minority.
}

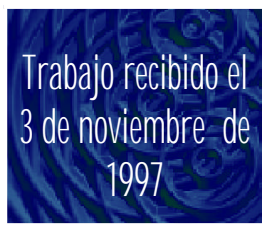




\section{INTRODUCCIÓN}

$\mathrm{D}$ esde comienzos del siglo XVIII, España va a experimentar una serie de cambios progresivos que culminan en las grandes reformas ilustradas de los ministros de Carlos III. La entronización de la dinastía borbónica supuso el comienzo de una andadura, caracterizada por una mayor intervención del Estado en la vida pública.

Este intervencionismo estatal, por lo que al ámbito cultural se refiere, comienza ya en los primeros años de la centuria y es su manifestación más significativa, la creación de una serie de instituciones culturales de claro cuño francés.

Entre estas nuevas instituciones, las Reales Academias serán elementos de modernidad frente al estancamiento de las universidades, a las que todavía no habían llegado los aires renovadores de la ciencia europea del XVII. Bajo la protección de Felipe V se crea en 1714 la Academia de la Lengua, la cual dirigirá sus esfuerzos a la elaboración de un Dicionario deAutaidades desde 1739. A ésta se suma la Academia de Medicina en 1731 y posteriormente la de Historia en 1738, fundándose seis años más tarde la de Nobles y Bellas Artes.

Este movimiento academicista tendrá su reflejo fuera de la capital del reino en donde se constituyen sociedades similares en poblaciones como Barcelona, Sevilla, Valencia y Zaragoza entre otras. ${ }^{1}$

También, desde los primeros momentos, se lleva a efecto la creación de una de las instituciones culturales más marcadamente dieciochesca, la Biblioteca Real, futura Biblioteca Nacional y cabeza del sistema bibliotecario español.

El ideario ilustrado de felicidad pública, utilidad y progreso marca, especialmente desde mediados de siglo, el camino a seguir por la minoría ilustrada, apoyada por la Corona en su quehacer reformista y renovador. Para esta minoría "la sociedad humana no es feliz porque haya uno u otro hombre grande, sino por la copia de hombres grandes, de hombres instruidos en las diferentes materias tenidas por necesarias para beneficio de la humanidad." 2 Se pretende, por tanto, lograr la felicidad de todos, la felicidad "pública" para lo que resulta imprescindible acometer una serie de reformas desde arriba, en beneficio de la mayoría.

Para Jovellanos, una de las figuras paradigmáticas de la vida cultural del siglo ilustrado, la primera y principal fuente de felicidad pública es sin duda la instrucción nacional "porque no se puede esconder que sin educación física no se podrán formar ciudadanos ágiles, robustos y esforzados; sin instrucción política y moral no podrán mejorar las leyes con que estos ciudadanos deben vivir seguros, ni el carácter y las costumbres que los han de hacer felices y virtuosos; y que sin ciencias prácticas y útiles no se podrán dirigir ni perfeccionar la agricultura, la in-

1 En 1729 y 1751 se fundan las Reales Academias de Buenas Letras de Barcelona y Sevilla; la Academia de Artes de San Carlos de Valencia en 1768 y la de San Luis de Zaragoza en 1792.

2 G. Marañón. Vida eHistaria 9a ed. Madrid: Espasa-Calpe, 1968, p.70. 
dustria y el comercio y las demás profesiones activas que los han de multiplicar, enriquecer y defender." 3

Aunque el Estado no estaba en condiciones, por carecer de los medios adecuados, de proporcionar una enseñanza para todos como un auténtico servicio público, sí trató de reformar el sistema educativo del momento. Se quiso extender y modernizar la educación elemental por todo el reino, ${ }^{4}$ se trató de renovar los estudios de latinidad y humanidades y nace la enseñanza profesional especializada con la creación de Escuelas de Náutica y Dibujo en diversas ciudades, al tiempo que las Sociedades Económicas ejercerán su acción educativa no sólo en la enseñanza primaria sino también en el campo práctico y utilitario de la instrucción profesional. 5 También la universidad y su reforma serán objeto de atención de regalistas ilustrados como Moñino o Campomanes en busca de su centralización y uniformidad si bien no lograron sacarla de su franca decadencia. ${ }^{6}$

Pero la reforma de la enseñanza debía completarse con otras actividades culturales desarrolladas por Academias y Sociedades y, como no, con la creación de gabinetes de Historia Natural, museos y jardines botánicos. En este abigarrado conjunto de reformas, la imprenta también debía jugar un papel fundamental en el desarrollo cultural perseguido tal y como lo manifiesta Carlos III en el preámbulo de algunas leyes dictadas bajo su mandato, buscando el fomento de ese arte y del comercio de libros, factores "que tanto contribuyen á la cultura general, y á la propagación de las Ciencias y conocimientos útiles[...]"7

Por último, la mejora del nivel cultural exigía como base estructural la apertura de bibliotecas públicas. En palabras de G arcía Morales, los ilustrados "[...] quisieron que los libros se encontrasen al alcance de la selecta e 'inmensa' minoría que encabezaba y regía un país en gran parte analfabeto. Para ello, comenzaron a desear, mejor que a abrir, restringidas - valga la paradoja- bibliotecas 'públicas'."8 De la importancia concedida a estos establecimientos por los hombres del siglo XVIII es buena muestra el hecho de que muchos de los políticos e intelectuales del momento poseyeron importantes colecciones bibliográficas. Además, los li-

3 G. M. de Jovellanos. "Bases para la formación de un Plan de Instrucción pública". En Obras B.A.E., t. XLVI, p.276, cit. por Varela, J. La Educación Ilustrada o como fabricar sujetos dóciles y útiles. Reista deEduracón no extraordinario, 1988, p.257.

4 Ver J. Ruiz Berrio. "La Educación del Pueblo Español en el proyecto de los Ilustrados". Rer. de Eduraaión no extraordinario, 1988, pp.165-191.

5 F. Aguilar Piñal. "Entre la Escuela y la Universidad: la enseñanza secundaria en el siglo XVIII". Rev. deEducaaón 1988, pp.227-243.

6 A. Álvarez de Morales. "La Universidad en la España de la Ilustración”. Rev. deEduraaón 1988, pp.469-477.

7 Noúsima recopiladớn delas leyes deEspaña. Dividida en XII libros Mandada formar por d Señor D. Carlos IV. Madrid: B.O.E., 1980, 6 vols. Repr. facsímil de la ed. de Madrid, 1805-1807, Libro VIII, Título XVI, Ley XXVI.

8 J. García Morales. "Un informe de Campomanes sobre las bibliotecas españolas". Rer. deArdivos, Biblicteasy Musees, 75, enero-diciembre, 1968-1972, p.92. 
bros y las bibliotecas constituyeron fundamentales instrumentos de trabajo en la elaboración de sus utópicos programas ilustrados.

El Padre Martín Sarmiento, el gran amigo de Feijoo, se muestra convencido de los beneficios que reportaría el establecimiento de bibliotecas públicas en las distintas poblaciones, ya que habrían de constituir el medio más apropiado para conseguir la felicidad de la República Literaria. A ellas, podrían acudir "a leer y estudiar los que no tienen libros, o los que no tienen todos los que necesitan para escribir alguna obra." 9 Ese "prematuro plan de bibliotecas", como lo denomina H. Escolar, trazado por el benedictino, nos parece un exponente altamente significativo del pensamiento reformista en donde la biblioteca debe desempeñar un claro papel instrumental, una potente herramienta educativa para formar individuos virtuosos y cultos propiciando la felicidad pública perseguida.

Esta sentida necesidad de renovación cultural queda plasmada a lo largo de la centuria en una serie de iniciativas en las que podemos observar las bases y primeros pasos de una organización bibliotecaria.

\section{FUndACIÓN DE LA REAL BIBLIOTECA}

La primera iniciativa borbónica en el campo bibliotecario va a tener lugar antes de concluida la G uerra de Sucesión. En efecto, el rey Felipe V en 1711 aprueba el proyecto de creación de una Librería Pública en Madrid, elaborado por su confesor el jesuita P. Robinet en colaboración, al parecer, con Melchor de Macanaz. Unos meses más tarde, el 1 de marzo de 1712, es abierta al público, si bien su creación oficial se produce en 1716 a través de un Real Decreto de 2 de enero expedido en Madrid por Felipe V.10

En el citado decreto de constitución, el monarca resuelve el establecimiento de dicha Librería Pública donde, junto a un buen número de libros impresos y manuscritos, se habrían de depositar "varios instrumentos Matemáticos, porción de monedas, medallas y otras curiosidades" siguiendo la costumbre de la época.

Para su sostenimiento se la dota "con ocho mil reales de renta á el año, asignándoles en las del tabaco y naipes del Reyno." Se prevé, asimismo, la dotación del personal que ha de servir en ella. El director general será el confesor del rey y bajo sus órdenes habrá un bibliotecario mayor, cuatro bibliotecarios, un administrador y dos escribientes, completando la plantilla un portero y un ayudante. Se

9 "Reflexiones literarias para una Biblioteca Real y para otras bibliotecas públicas hechas... en el mes de diciembre del año 1743". SeminarioEnudito, XX I, pp.99-273, cit. por Escolar, H. Histaria delas Biblictecas Salamanca; Madrid: F.G.S.R., 1990, p.387.

10 L. García Ejarque. Biblioteca Nacional de España. Bdeén dela ANABAD, 42, 3-4, 1992, p.206. Sobre la creación e historia de la B.N. es abundante la bibliografía tal y como se desprende de la recopilación llevada a cabo por Crespo Tobarra, C. Ensayo de una bibliografía sobre la Biblioteca Nacional. Bded́n dela ANABAD, 42, 1, 1992, p.234. Decreto de constitución, Libro VIII, Título XIX, Ley I de la Noúsima recopilación 
especifican los sueldos de cada uno de ellos, con cargo a la dotación asignada, la cual permitirá también la adquisición de nuevos fondos.

Por último, se aprueban las constituciones o estatutos del establecimiento, redactados por el padre $\mathrm{G}$ uillermo Daubenton, confesor del rey, a lo largo de sus veinte puntos, se fijan las obligaciones del personal, la utilización de los fondos y el horario de apertura11 (ver anexo I).

Las directrices para la adquisición de fondos bibliográficos quedará configurada no sólo mediante la compra a cargo del presupuesto de la propia biblioteca como ya se ha señalado, sino también por medio de incautaciones, donaciones y la asignación o concesión de lo que más tarde se denominaría depósito legal.

Efectivamente, la confiscación de algunas bibliotecas particulares de nobles que abandonaron el país, tras el triunfo borbónico sobre el archiduque Carlos, parece un hecho confirmado por Melchor de Macanaz, quien en su testamento nos dice como él "se encargó de recoger las bibliotecas de los emigrados" que posteriormente pasaron a formar parte de la nueva institución. ${ }^{12}$ Éste fue el destino de la biblioteca del Marqués de Mondéjar, formada por más de 5000 volúmenes, algunos de ellos manuscritos, confiscados por mandato real en 1708,13 así como la del duque de Uceda y la del arzobispo de Valencia, ambas incautadas en 1711 y 1712, respectivamente. 14

Por su parte, la asignación del depósito legal supuso para la Librería Real una fuente permanente de nuevos ingresos a partir de la promulgación de la Real Cédula de 26 de julio de 1716. En ella se ordenaba la entrega de un ejemplar encuadernado de todo libro que se imprimiese, del mismo modo que se venía haciendo desde 1619 con destino a la Biblioteca del Monasterio de El Escorial. El objetivo de esta medida es puesto de manifiesto por el propio texto legal: "[...] para que cada día se vaya perfeccionando esta obra tan de mi agrado y bien público". Además, la norma tiene un carácter retroactivo, ya que se debían depositar en la "Biblioteca todos los libros y demás impresiones que se hubieren dado á la estampa desde el año de 1711 en que tuvo principio esta Biblioteca." 15

De los beneficios que el establecimiento de esta institución real debió reportar a la nación nos da cuenta el propio Padre Sarmiento en sus ya citadas "Reflexiones literarias" al señalar que a su "establecimiento, que al principio pasó por cu-

11 Fundacón y Estatutos dela Libreia Publica ded Rey N. Señor D. PhdipeV Rey deEspaña. En Madrid: en la O ficina de Francisco de el Hierro, 1716, p.8-14.

12 H. Escolar, Opcit, p.375.

13 Esta biblioteca es citada por Campomanes en su "Noticia abreviada de las bibliotecas y monetarios de España:" "[...]la librería del Marqués fue numerosa y exquisita, conservándose en el día incorporada a la Biblioteca Real", cap.IV, transcrito por García Morales, J. Un informe de Campomanes sobre las bibliotecas españolas. Rev. deArdivos, Biblictecas y Musees 75, enero-diciembre, 1968-1972, p.118.

14 L. García Ejarque. Opait, p.211.

15 Noúsima Recopilacoón Libro VIII, Título XVI, Ley XXXVI. 
riosidad, le siguió la curiosidad de ir a ver los libros materialmente colocados; a ésta la de abrirlos y revolverlos; a ésta el apetito de leer algo; a éste la afición de leer mucho, y a todos el deseo de comprar otros semejantes para leerlos con más comodidad en su casa, o la solicitud de comprar otros libros que allí vió citados y aún no se hallaban en la Real Biblioteca. Finalmente, comenzaron a descubrirse compradores de libros curiosos, y no faltaron libreros extranjeros que viniesen a establecerse en Madrid."16

En parecidos términos se expresa años más tarde (1788) el conde de Campomanes: "Las bibliotecas públicas se han creado generalmente en España durante este siglo, lo que debe atribuirse al ejemplo de la Biblioteca del Rey y al provecho que de su manifestación diaria resulta a las gentes literatas, por lo común pobres y faltas de medios para adquirir libros, especialmente en los primeros años, que es cuando pueden leerlos con mayor fruto." 17

\section{LA ORGANIZACIÓN BIBLIOTECARIA EN LA SEGUNDA MITAD DEL SIGLO XVIII}

Si los primeros lustros del XVIII vienen caracterizados en el campo bibliotecario por la creación y consolidación de la futura Biblioteca Nacional, a partir del reinado de Carlos III, los ilustrados españoles pondrán de manifiesto un interés creciente por dotar al país de nuevas bibliotecas al tiempo que tratarán de potenciar las ya existentes. La labor legislativa que orienta las directrices bibliotecarias se va a centrar fundamentalmente en un impulso renovado hacia la Biblioteca Real de Madrid y en la organización de los ricos fondos bibliográficos dejados por los jesuitas tras la expulsión de la Compañía en 1767.

\section{C arlos III y la Real Biblioteca}

La primera disposición tomada por el monarca tras su llegada en 1759 será la aprobación por una Real Cédula de 11 de diciembre de 176118 de unas nuevas constituciones elaboradas por el Bibliotecario Mayor Juan de Santander (ver anexo II). En ellas, a lo largo de sus 16 artículos, se trata de reglamentar con una mayor minuciosidad la "fundación Real[...] una de las más preciosas alhajas de la Corona, de que resulta tanto beneficio y honor al Estado."

Se reitera, en primer lugar, su carácter de Propiedad Real, por lo que todas sus dependencias y negocios correrán a cargo del "Secretario del D espacho Universal que tuviere á su cargo las Casas Reales". También ratifica el rey, aunque ampliándolo, el privilegio de recibir un ejemplar "de todas las obras, libros, papeles y escritos de qualquiera clase, y por pequeños que sean, que se impriman ó reim-

16 Fray Martín Sarmiento. "Reflexiones literarias..." SeminarioEnudito XXI, dic. 1743, cit. de Escolar, H., qpat, p.387.

17 Noticia abreviada delas biblictecas..., cap.V. Opait, p.122.

18 Noúsima recopilación... Libro VIII, Título XIX , Ley II. 
priman en los Reynos y dominios de S.M." Para evitar el incumplimiento de la norma legal "deberán siempre todos los impresores reservar en su poder un exemplar de qualquier obra, libro, mapa ó papel que impriman, y enviarle á la Real Biblioteca; sin cuyo recibo no pasarán á entregar la obra ó libro á su autor, ó al dueño de la impresión, ni se podrá poner en gazeta, venderse ni hacerse uso alguno de ella."

El artículo tercero, amplía aún más la entrega de impresos a "todas las ordenanzas, reglamentos, pragmáticas, cédulas, decretos y demás papeles que de orden de S.M. se imprimieren por las Secretarías del D espacho universal, Consejos y Tribunales de estos Reynos[...]"

Además, para facilitar el ingreso por compra de nuevos fondos se ratifica el privilegio de tanteo otorgado a la biblioteca en $1750^{19}$ sobre la venta de bibliotecas particulares. Con ello se pretendía que la Biblioteca Real se erigiese en primer comprador, y por tanto en situación de privilegio sobre la adquisición de tales fondos. Los dueños no podían efectuar su venta hasta 15 días más tarde, plazo aprovechado por el Bibliotecario Mayor para decidir sobre la conveniencia o no de su compra.

Para llevar a cabo estas y otras adquisiciones se dota a esta institución con 50.000 reales al año, completando el presupuesto 39.356 reales "para los gastos precisos anuales que debe hacer la Real Biblioteca, así para su conservación como para el servicio del Público."

Estos nuevos estatutos no se olvidan de determinar las medidas de custodia, el personal y las competencias que se les asignan, así como la confección de índices, catálogos e inventarios que son necesarios mantener.20

19 Real Resolución a consulta del Consejo de 17 de junio de 1750 por la que "los tasadores de librerías hayan de avisar inmediatamennte que ejecuten las tasas de las que vendiesen 0 tasasen a este fin a V . para que, en el término preciso de ocho días, reconocidas las tasas que se le han de remitir, y registrados los libros, faltando estos en la Real Biblioteca, use del derecho de tanteo en dicho término, de modo que, pasando sin haberlo ejecutado, puedan los dueños usar del que les corresponde para la venta, en uso de su libertad, quedando por este medio salvo el derecho de tanteo a la Real Biblioteca, en el caso de faltarle algunos libros, y evitando el perjuicio que de la dilación se seguiría con necesidad a los dueños de ellos, quienes en manera alguna podrán disponer de dichos libros para venderlos sin que procedan las referidas circunstancias", cit. de García Ejarque, L. Opait, p.212-213.

20 En este punto ver la obra de H. Escolar ya citada. 
El 19 de diciembre de ese mismo año, una Real O rden reitera el cumplimiento de la entrega de impresos a la biblioteca pero ampliándose la normativa a "las estampas, que se publicasen sueltas 0 en colecciones." 21

\section{Las bibliotecas de los jesuitas}

La impronta dejada por la Compañía de Jesús en el campo bibliotecario español puede resumirse en tres puntos esenciales:

1 ํㅡㄹ constitución y posterior desarrollo de la Biblioteca Real. En este punto debemos recordar cómo fue precisamente un jesuita, el padre Pedro Robinet, quien realizó la propuesta de creación de la misma al rey Felipe $\mathrm{V}$ y, posteriormente, ejercieron como directores diversos miembros de la Compañía. ${ }^{22}$

$2^{0}$ D esde su fundación, esta orden religiosa otorgará a la biblioteca un significativo papel en sus programas de formación y enseñanza. La actividad docente desempeñada por la Compañía en los Colegios de Primeras Letras, Latinidad y Humanidades y en buena parte de las universidades españolas hicieron de ella un eje fundamental en este campo desde mediados del siglo XVI. Inseparables de esta actividad educadora eran las bibliotecas, ya que las propias normas fundacionales y la regulación de los estudios por la Ratio Studionumasí lo requerían: "Haya librería, si se puede general, de los colegios y tengan llave de ella los que el rector juzgase deben tenerla. Sin esto los particulares deben tener los libros que les fueren necesarios [...] Con esto no los deben glosar y tenga quenta dellos el que tiene cargo de los libros." 23

La documentación aportada y analizada por Bartolomé Martínez sobre las librerías jesuíticas nos muestra claramente cómo cada uno de los Colegios de la Compañía situados en las distintas provincias (Castilla, Toledo, Andalucía y Aragón), contaron con bibliotecas de abundantes y variados fondos. La forma de adquisición de los mismos, determinada por la propia Ratio Studianm se efectuaba por medio de las rentas fundacionales e incluso partidas extraordinarias en algunos casos, las frecuentes donaciones de bibliotecas particulares y por último los libros impresos en las imprentas de los jesuitas especialmente a

21 Libro VIII, Título XVI, Ley XXXVIII de la Noúsima recopilacón

22 Señala C. Eguía Ruiz cómo los jesuitas estuvieron en la dirección de esta institución al menos 40 años: P. Robinet (1712), E. Le Compaseur (1715), G. Daubenton (1716), G. Bermúdez (1723), J.A. Lefevre (1724), F. Rávago (1751). "Los jesuítas, proveedores de bibliotecas. Recuento de muchos espolios". Razóny Fe, 1944, p.234.

23 Constituciones Sti. Ignatii, parte IV, cap.6, art.7. Monumenta Ignatiana, serie 3, t.III, cit. por Bartolomé Martínez, B. "Las librerías e imprentas de los jesuítas (1540-1767): una aportación notable a la cultura española”. Hispania Sacra, 40, 1988, p.316. 
partir del siglo XVIII.24

La naturaleza de los fondos, según vemos por los libros de cuentas conservados de los distintos colegios, se adaptan a las necesidades didácticas, de estudio y predicación, tareas a las que estuvo abocada la Orden desde su fundación. Por otro lado, los catálogos de sus librerías mencionan, junto a libros de espiritualidad y sermones, los tratados científicos y las producciones literarias. 25

Sobre la riqueza de los libros que surtían algunas de estas bibliotecas, resulta significativo el siguiente texto referido al Colegio de Granada, uno de los más prestigiosos por la presencia de la casa provincial y noviciado: "[...] con lo que ha juntado buen número de libros de todas las facultades pues pasan de cinco mil cuerpos los que por el índice se hallan oy en la librería y todos exquisitos y curiosamente enquadernados y si tan bueno es el número de libros impresos que ay no es de menor estima lo manuscrito que en ella se ha puesto este año de 1640 y entre ellos libros del arzobispo de Toledo y de Luis de Molina con la disputa de auxiliis." 26 También la variedad y calidad de la Biblioteca del Colegio Imperial de Madrid debió ser considerable ya que según P. Burruel "hay la mayor y mejor librería de la Corte fuera de la Real y un archivo nada desfrutado de mil curiosidades." 27

3o Estos fondos jesuíticos constituirán la base de la reorganización bibliotecaria española llevada a cabo por los ilustrados, como veremos a continuación.

24 B. Bartolomé Martínez. quat, p.317-332. La Ratio Studionumseñala que "para que no falten a los nuestros el número de libros necesarios conviene fundar rentas anuales del propio colegio 0 de otra parte para ampliar la biblioteca y bajo ningún concepto se puede aplicar a otro destino". También las donaciones efectuadas por los fundadores de los colegios o por particulares afectos a la Compañía, fueron un medio de adquisición de fondos importante, como vemos en este documento de donación fechado el 17 de abril de 1599: "Notorio sea a todos que yo D on Antonio Zapata por la gracia de Dios, Obispo de Pamplona, dejo de mi libre voluntad y por la que tengo y he tenido a la sagrada religión de la Compañía de Jesús, hago desde agora para siempre gracia y donación pura, perfecta irrevocable que el derecho llama inter vivos a la dicha Compañía de Jesús y al colegio della villa de Madrid corte de su Magestad de mi librería que tengo toda en los estantes en que está que son ciento y quarenta caxones... y de los globos, spheras, mapas e instrumentos de cosmographia que ansimesmo tengo... y pongo por condición onerosa o por obligación recíproca, y inbiolable que los dichos libros y lo demás contenido en esta donación no se pueda quitar de dicho colegio". En cuanto a los fondos salidos de las imprentas jesuíticas fueron esencialmente manuales de humanidades clásicas, sobre todo latinas, requeridos por el programa de estudios y libros de piedad.

25 Idam p.322-323.

26 A.H.N. Secc.Jes., lib,773, cit. de Bartolomé Martínez, B. Las libreías eimprentas..., p.319-320.

27 A. Echánove Tuero. La preparacón inteectual de P. Marcos Andrés Bumid. Madrid, 1971, p.40, cit. de Bartolomé Martínez, B. Opcit,p.352. La biblioteca del Colegio Imperial es estudiada por J. Simón Díaz en Histaria dd CdegjoImpeial deMadrid 2 vols. Madrid, 1959. 


\section{Reorganización de los fondos de la C ompañía}

El gran artífice de esta reforma y reestructuración el conde de Campomanes, buen conocedor de las riquezas bibliográficas de los jesuitas, se va a plantear, incluso antes de la pragmática de expulsión de 2 de abril de 1767, la necesidad de conseguir pruebas con destino a "la pesquisa reservada" que debía justificar la expulsión de la Compañía de los reinos de España y de las Indias. En las librerías y archivos de los jesuitas pensó el fiscal Campomanes encontrar las pruebas inculpatorias que buscaba y así, en el Consejo Extraordinario de 29 de enero de 1767, propuso la incautación de las bibliotecas y papeles en los siguientes términos: "Procederá sucesivamente (el ejecutor), junto con los PP. Superiores y Procurador, a la judicial ocupación de Archivos, papeles de toda especie, Biblioteca común, libros y escritorios de aposentos, poniendo con distinción los que pertenezcan a cada jesuita, juntándolos en uno o más lugares; entregando in continenti las llaves al juez de comisión." 28

Al parecer, la incautación perseguía también, dada la riqueza de tales depósitos, conseguir los fondos necesarios que hiciesen factible, desde un punto de vista económico, el extrañamiento perseguido. La ocupación y venta de las temporalidades, que se traducían en un sustancioso patrimonio, era pues un requisito inseparable de las medidas de extinción de los jesuitas.

Así las cosas, veinte días después de la expulsión, se dicta una Provisión encaminada a normalizar la actuación de delegados y ejecutores de la medida propuesta para los fondos incautados. En efecto, el 23 de abril de 1767, una Real Cédula recoge la "Instrucción de lo que se deberá observar, para inventariar los Libros, y Papeles existentes en las Casas que hán sido de los Regulares de la Compañía, en todos los D ominios de Su Magestad." 29

A lo largo de veinticuatro capítulos se detalla el método que ha de seguirse en tan delicada tarea para no "caer en confusión", encomendándose a personas "versadas en negocios y literatura", y no entregando "esta diligencia al cuidado de los Escribanos, agenos por lo comun de literatura, y del Idioma Latino, y demas lenguas en que se hallan los mejores Libros." 30

Aunque la instrucción va dirigida a libros y papeles, nos interesa ahora señalar el mecanismo propuesto para el inventario de los materiales bibliográficos.

En primer lugar, se hace un clara distinción entre los fondos impresos y manuscritos que han de figurar en índices separados.

28 C. Eguía Ruiz. "Los jesuitas, proveedores de bibliotecas. Recuento de muchos espolios”. Razón yFe, 1944, p.234.

29 Cdeción General delas providenias hasta aquí tomadas por d Gdiemo sdbred estrañamientoy caupación de temparalidades delos Regulares dela Compañía..., Parte Primera. Madrid: Imprenta Real de la G azeta, 1767, p.46-51.

30 Idem, p.46-47. 
En cuanto a los impresos, el apellido del autor y su nombre será el punto de acceso utilizado en la ordenación alfabética del índice. Seguidamente, se transcribirá el título completo, lugar y año de la edición, con objeto de conocer si se trata de la primera edición o de ediciones posteriores. Estos datos van a permitir la identificación inmediata de todos los fondos, cuestión fundamental para el fiscal Campomanes quien no puede ocultar en su instrucción el conocimiento e interés que como bibliófilo despierta en él tan rico patrimonio.

En cuanto a los manuscritos, será necesario consignar las primeras y últimas líneas del texto, así como el número de sus folios. Le interesa al fiscal tener un conocimiento exacto de aquellos códices en pergamino avitelado "en letra gótica, ó monacal antigua" por lo que tales datos deberán figurar en el índice de manuscritos. Además, las obras encuadernadas conjuntamente deberán ser revisadas con atención, anotando el principio y fin de cada una de ellas.

Para una mayor facilidad de localización se anotará en cada obra el número asignado en el índice ya sea de impresos o de manuscritos.

Este inventario de fondos bibliográficos afectará tanto a los procedentes de las librerías como a los de los aposentos de los padres. Todos ellos deberán ser depositados en la biblioteca del correspondiente Colegio o en otra sala con amplitud suficiente, quedando bajo llave, en espera de enviarlos al destino que se les asigne.

Por último, los ejemplares depositados en las porterías e imprentas de la Compañía deberán también ser inventariados (ver anexo III).

La aplicación de estas instrucciones en la catalogación de los fondos dio origen a una importante tarea de ordenación bibliográfica que puso claramente de manifiesto la sospechada riqueza del patrimonio de los jesuitas españoles de la época. 31

El paso siguiente en la tarea reorganizadora planteada por Campomanes debía ser la distribución de aquellos ricos fondos en librerías o bibliotecas. Fue preciso, por tanto, determinar el destino que debía tener el patrimonio incautado. Aunque ya, en esta Real Cédula en su artículo XXIV se mencionan a las universidades como posibles centros receptores, hasta 1772 no se dará el marco normativo que regule esta interesante cuestión.

En efecto, el 2 de mayo de ese año se expide una Real Provisión 32 donde se contiene la instrucción por la que se regula la entrega de los fondos jesuíticos a diversas instituciones. En líneas generales la distribución es la siguiente:

31 B. Bartolomé Martínez. Opait, p.375.

32 Real Provisión de los Señores del Consejo... en que se incluye la Instrucción formada sobre el destino de todas las Librerías existentes en las Casas, Colegios, y Residencias que los Regulares... En: Cdeccón General delas providenias tamadas sobred estrañamientoy oupación deTemporalidades de Regulares dela extinguida arden dela Compeñía que exîstian en los Dominios de S.M Parte Q uarta. Madrid: Imprenta Real de la G azeta, 1774, p.39-46. 
10 Bibliotecas Públicas E piscopales: a ellas irán los libros de los jesuitas que todavía no se hubiesen asignado, con excepción hecha de los procedentes de los Colegios de Loyola y Villagarcía que deberán ser aplicados a los Seminarios de Misiones.

2ํㅡㄹ Bibliotecas Universitarias: Las universidades recientemente aprobadas acogerán las "librerías de las Casas y Colegios que tenían los expulsos en los Pueblos donde exîsten, debiendo servir para la educación de sus estudiantes, y funciones literarias". Como excepción, la Universidad de Palma, pese a no ser de las aprobadas, podrá recibir los fondos bibliográficos procedentes de los dos colegios jesuíticos de la isla.

3o Biblioteca del Seminario de Toledo: el antiguo colegio toledano convertido en Seminario "Clerical y de Corrección" pasa a detentar la Librería jesuítica "para uso de sus Directores, Alumnos, é Individuos".

4ํArchivo de los Reales Estudios de San Isidro: en él se depositarán ordenadamente "los papeles manuscritos y de pura disciplina interior y exterior de los Regulares expulsos, y los demás que miren á su gobierno político", así como los "títulos de pertenencias y derechos temporales"33 (ver anexo IV).

Esta reordenación de los fondos debía realizarse conforme a unas reglas determinadas y así, las entregas de materiales serían efectuadas por las Juntas Municipales y Provinciales. Éstas pedirían el correspondiente recibo de entrega y previo a ello efectuarían el reconocimiento de los libros que contuviesen "máxîmas, y doctrinas perjudiciales á el D ogma, Religion, buenas costumbres, y regalías de S.M." Todos los fondos con estas características serían depositados por separado en las bibliotecas de destino. ${ }^{34}$

Una vez efectuada la distribución, las instituciones más beneficiadas fueron, sin duda, las universidades, tanto mayores como menores ubicadas en aquellas localidades donde estuvieron los distintos Colegios de la Compañía. Junto a ellas, seminarios, bibliotecas episcopales y algunos conventos se vieron favorecidos en el reparto.

Por otro lado, algunos de los colegios jesuíticos que continuaron su actividad docente fuera ya de la órbita de la Compañía dispusieron de sus respectivos fondos bibliotecarios.

33 El cumplimiento del punto $\mathrm{V}$ de la Instrucción hizo posible la creación de ese riquísimo archivo "nada desfrutado de mil curiosidades" del que habla el P.Burriel, ver cita 27.

34 Cdecióngeneral delas providenias.. Madrid: Imprenta Real de la G azeta, 1774, p.45. 


\section{PANORAMA DE LAS BIBLIOTECAS Y SU REFLEJO EN LA LEGISLACIÓN}

\section{Biblioteca de los Reales Estudios de San Isidro}

Muchos de los colegios de latinidad y retórica de los jesuitas fueron secularizados a partir de la expulsión, 35 y tras reestructurarse sus enseñanzas, conservaron y siguieron utilizando sus librerías. 36 E s éste el caso del Colegio Imperial de Madrid, fundado por Felipe IV en 1625, que cambia su nombre por el de Reales Estudios de San Isidro y que reabre sus puertas en 1770.37

La biblioteca constituía, sin duda, uno de los ejes de los nuevos estudios, según podemos deducir del texto recogido en el Real Decreto de 19 de enero de 1770:38

Mando, que para el mayor adelantamiento de los Reales Estudios fundados en el Colegio Imperial, que fué de los Regulares de la Compañía, y he mandado restablecer, se erija una biblioteca pública, la que había en dicho Colegio, así para el uso de los maestros y profesores, y de sus discípulos, como para el común de los demás estudiosos que quieran concurrir á ella; y para su ordenación, cuidado y asistencia, quiero, que se nombre un Bibliotecario, que esté en la Biblioteca las horas que se le destinen por la mañana y por la tarde, con la obligación de enseñar la Historia Literaria, y un segundo Bibliotecario para ayudar al primero.

Por otro lado, el decreto de reestablecimiento de los Reales Estudios señala que el cargo de bibliotecario no será por concurso sino que el Consejo propondrá al rey "algunos sugetos acreditados por su erudición, virtud, entereza, zelo y deseo del aprovechamiento de la juventud," para que él elija y nombre al que juzgue más útil, y más conforme a sus reales intenciones. 39

Años más tarde, el monarca insiste en la necesidad de que dicha biblioteca tenga el carácter de pública. Son dos las razones que la hacen idónea para ello:

35 Por Provisión del Consejo de 5 de octubre de 1767 se procedió "á subrogar la enseñanza de Primeras letras, Latinidad y Retórica que se hallaba al cargo de estos (los jesuitas), en maestros y preceptores seculares á oposición. Noúsima recopilación..., t.IV , p.15, nota 3.

36 Para Aguilar Piñal, pese al interés mostrado por Campomanes en este punto, no debió ser fácil poner nuevamente en marcha estos centros docentes:"En unos casos, los edificios se destinaron a hospicio, o casa de misericordia; en otros a cuartel, hospital o centro universitario; los más terminaron vencidos por la ruina y el abandono. Solo unos pocos renovaron la función docente a cargo de profesores seculares". Opat, p.233.

37 Idem En él se dieron cita los mejores profesores (convocatorias públicas de carácter nacional) del país, quedando incluso en algunas disciplinas por encima de algunos centros universitarios al contar con cátedras de D erecho natural y de gentes, de física experimental (fue el primero en introducir esta disciplina), matemáticas, griego, árabe y hebreo, retórica y poética "además de otra de absoluta novedad, vinculada al bibliotecario del centro: la cátedra de historia literaria..."

38 Libro VIII, Título XIX, Ley III de la Nov́sima recopilacón

39 Libro VIII, Título II, Ley III. 
1 a La importante riqueza de sus fondos. 40

$2^{\text {a }}$ Su adecuada y estratégica ubicación que venía a facilitar la utilización frecuente del establecimiento.

El texto del R.D. de 8 de octubre de 1785 lo expresa en los siguientes términos:

Estando como estoy informado de que en los Reales Estudios restablecidos en el Colegio Imperial, que fué de los Regulares de la Compañía, con los caudales que ha producido la venta de los libros duplicados y sobrantes se ha formado y construido una Biblioteca muy capaz, en que estan colocados mas de treinta y quatro mil volúmenes; la qual, por el parage en que está situada, se halla en buena proporción para ser freqüentada por las personas estudiosas y aplicadas, pudiendo ser por lo mismo de mucha utilidad: á fin de que esta Biblioteca se abra y destine para el servicio del Público, lo que quiero se haga inmediatamente, encargo, que entre los dos Bibliotecarios primero y segundo se me proponga el método, horas y demas particulares concernientes al buen uso y gobierno de la Biblioteca. ${ }^{41}$

En el incremento de la Biblioteca de los Reales Estudios de San Isidro debió jugar un papel importante la entrega obligatoria de ejemplares de los nuevos libros impresos. Este privilegio, concedido por los reyes a la Biblioteca del Escorial y posteriormente a la Biblioteca Real, se hará extensivo a partir de 1786 a los Reales Estudios por R.O . de 1 de enero. ${ }^{42}$ Se equipara así la nueva biblioteca pública con las antedichas fundaciones reales:

Atendiendo favorablemente al mejor surtimiento de la Biblioteca de los Estudios Reales de Madrid, en consideracion a la pública utilidad que resulta de este establecimiento; he resuelto, que todos los que impriman alguna obra en el Reyno, de qualquier género que sea, hayan de dar un exemplar de ella á la dicha Biblioteca; y solo con esta condicion se les conceda licencia para la impresion del mismo modo que se practica en favor de la antigua Biblioteca Real de esta Corte, y de la del Real Monasterio de S. Lorenzo del Escorial.

\section{Bibliotecas U niversitarias}

También las universidades van a recibir parte del legado bibliográfico jesuítico. La necesaria reforma de la Enseñanza Superior asumida por Carlos III quedará tan sólo en tímidos tanteos que, sin embargo, inspirarán en gran medida los planes de reforma de la centuria siguiente. La decadencia de los Colegios Mayores

40 Según Eguía Ruiz, la biblioteca del Colegio Imperial abarcaba todas las disciplinas siendo una de las primeras de España al haber recibido desde el primer momento la protección real. También los jesuitas la mimaron y acrecentaron por diversos procedimientos. Así, cuando en la centuria siguiente José Bartolomé G allardo realizó la revisión de la misma con objeto de llevar fondos útiles a la recién creada Biblioteca de las Cortes, fueron trasladados un buen número de volúmenes, entre ellos manuscritos, muchos de ellos iluminados, junto a impresos raros y de gran valor. Opait,p.242-243.

41 Libro VIII, Título XIX, Ley IV de la Noúsimarecopilación

42 Libro VIII, Título XVI, Ley XXXIX. 
quedará amortiguada con la reforma carolina de 1777, pero la problemática de la propia universidad, con sus cátedras mal dotadas, la escasa preparación de su profesorado y el estancamiento de sus planes de estudios impidió a los ilustrados sacar a la universidad española de su tradicional postración.

Pese a ello, la falta de recursos económicos pudo ser paliada, en parte, con el expolio de los bienes de la Compañía y así muchos colegios y casas de los jesuitas pasaron a acoger en sus muros enseñanzas universitarias al tiempo que las bibliotecas de estos centros van a nutrirse de nuevos ingresos, en ocasiones cuantiosos, activando su funcionalidad como centros del saber.

La situación precaria de muchas Bibliotecas de Facultades Mayores y Menores podemos constatarla en las instrucciones y reglas dictadas a los Directores de las Universidades en febrero de 1769; dice así el texto legal en su artículo 22:

También puede faltar Biblioteca, ó no ser tan completa como requiere el esplendor y la enseñanza de un Estudio general: y á este fin propondrá también el Director lo conveniente, con atención á los fondos, y á otros medios que se puedan proporcionar. ${ }^{43}$

Ante este panorama no duda el fiscal Campomanes en sus instrucciones designar a las universidades como receptoras de fondos jesuíticos ya que "D onde quiera que hubiere Univesidades podrá ser útil agregar a ellas los Libros que se hallaren en las Casas de la Compañía, situadas en los mismos Pueblos; y para poderlo decretar el Consejo con conocimiento, consultará el Executor, de acuerdo los Diputadbs, que nombre el Claustro, que será un graduado de cada Facultad." 44

El estudio realizado por Eguía Ruiz pone de manifiesto cómo el cumplimiento de la Instrucción de 22 de abril de 1767 vino a incrementar los fondos universitarios. El conde de Campomanes, en su informe de 1788 sobre las bibliotecas españolas, nos refiere el rico contenido de algunas bibliotecas universitarias como Salamanca, Alcalá, Valladolid y Santiago y añade que todas ellas fueron receptoras de fondos de los jesuitas. 45

La trascendencia de esta medida para algunas de las anquilosadas bibliotecas universitarias queda patente en el testimonio escrito en 1881 por el Director de la Biblioteca de la Universidad de Valladolid:

Aunque desde la fundación de esta Universidad es conjeturable que debió existir biblioteca, no mereció ésta nombre de tal hasta el enriquecimiento fundamental obtenido en ella por la aplicación que se le hizo de los libros procedentes de la suprimida Compañía de Jesús en cumplimiento de la Real Orden de Carlos III. 46

43 Libro VIII, Título V, Ley II.

44 Instrucción de lo que se deberá observar, para inventariar los libros, y papeles existentes... art.XXIV. En: Coleción General delas providenias hasta aquí tomadas.. Parte Primera. Madrid: Imprenta Real de la Gazeta, 1767.

45 Notida abreviada delas biblictecas.., Opait, p.123.

46 C. Eguía Ruiz. Opait, p.240. 
También los ilustrados analizarán la formación de bibliotecas en centros universitarios de nueva creación. Es el caso de los Colegios de Cirugía de Cádiz (1748), el de Barcelona (1760) y el de San Carlos de Madrid (1780). A ellos les seguirán años más tarde los fundados por Carlos IV en Burgos y Santiago (1804) que vendrían a completar el panorama formativo en esta materia.

Todos ellos debían contar con fondos bibliográficos especializados, según recoge la Real Cédula de 6 de mayo de 1804, donde se estudia el establecimiento de bibliotecas públicas en estos centros de enseñanza:

En cada uno de los Colegios de Cirugía ha de haber una oficina destinada para Biblioteca; en la qual se procurará tener todas las mejores obras de la Facultad y sus ramos auxîliares para la instruccion pública, haciéndose sucesivamente una colección de las que se consideren más convenientes á este fin: y el empleo de Bibliotecario recaerá en uno de los catedráticos supemumerarios; el qual, ú otro profesor del Colegio, le substituirá en los casos de enfermedad ó ausencia, para que no se falte al cumplimiento de las obligaciones de este destino. ${ }^{47}$

El carácter de estas bibliotecas era público, permitiendo por ello la entrada a toda "persona decente, sea ó no de la profesion" y sus fondos estaban excluidos de préstamo. Las ordenanzas establecen también el horario de la misma que varía según los meses de año. El bibliotecario deberá mantener dos índices alfabéticos, autores y materias con indicación de la signatura topográfica (ver anexo V).

El apoyo a las ciencias útiles se manifiesta en la creación de una Cátedra de Clínica o Medicina Práctica en el Hospital General de la Corte. Como no podía ser menos, se la dota de biblioteca y se le otorga el privilegio de ingresar en su fondo un ejemplar de todo lo que se imprima:

Habiéndome servido establecer en beneficio de la humanidad, y para mayor y mas acertado alivio de las dolencias de mis amados vasallos, una cátedra de Clínica ó Medicina práctica en el Hospital general de esta Corte, en la que los profesores puedan acabar de adquirir en esta Ciencia la posible perfeccion; he resuelto al mismo tiempo, que para el mayor complemento de la coleccion de obras, que formarán la Biblioteca de esta cátedra se exîja de los autores de quanto se imprima en mis Reales dominios un exemplar de sus escritos con destino á ellas. ${ }^{48}$

\section{Bibliotecas públicas episcopales}

No escapaba a los ilustrados españoles la riqueza de las bibliotecas episcopales, que desde la Edad Media habían constituido importantísimos conjuntos de materiales bibliográficos. Es por esto que ante la necesidad de incrementar las bibliotecas públicas en el reino, las autoridades van a fijar sus ojos en dichas instituciones, normalizando el desenvolvimiento de las mismas. Así, en 1770, con motivo de regular el Patrimonio de las Mitras, se otorga un reglamento en el que

47 Libro VIII, Título XIX, Ley V de la Novísima recopilacón

48 Libro VIII, Título XVI, Ley XL. 
se recogen junto a otros bienes patrimoniales los libros conservados en los palacios episcopales.

En adelante, según la Real Cédula de 17 de febrero, habrá de reservarse "perpetuamente á favor de las Mitras todas las librerías de los Prelados, que se encontrasen al tiempo de su muerte, para el uso de sus sucesores y familia, y para el aprovechamiento público de sus diocesanos, principalmente de aquellos que se dedican al estudio de la predicacion, y demas exercicios del pasto espiritual de las almas." 49

Son dos los objetivos que persigue la aplicación de esta norma. En primer lugar, las surtidas bibliotecas de los obispos no podrán ser enajenadas por los familiares del prelado una vez muerto. Este hecho era al parecer frecuente y originaba pérdidas irreparables en las bibliotecas episcopales. En segundo lugar, aquellos fondos pasarán a ser públicos y su acceso ya no queda restringido a un grupo privilegiado, abriéndose ahora a todos los que quisieran acudir a ella.

Por ello se determina que, a la muerte del prelado se forme un índice de los libros existentes, con indicación de autor, materia y lugar de impresión.

Se crea el cargo de bibliotecario que será nombrado por el rey a propuesta de los prelados, a través de una terna y se especifica su remuneración (de 400 a 800 ducados) que correrá a cargo del fondo de la Mitra.50 Se establece, por último, el número de horas de apertura del establecimiento, respetando los días festivos.

A partir de ese momento, este tipo de bibliotecas, como establecimientos públicos, quedan bajo la tutela y control del monarca (ver anexo VI).

El legado jesuítico vino también a enriquecer los anaqueles de aquellas bibliotecas eclesiásticas, ahora públicas y, así, la Instrucción de 1772, antes mencionada, recoge la aplicación de los libros de los jesuitas, aún no asignados, a las episcopales. Las Juntas Provinciales y Municipales de los respectivos territorios dispusieron "la entrega de Librerías á los Reverendos Arzobispos y O bispos", siguiendo la orden recibida.

Un ejemplo significativo recogido por Eguía Ruiz es el caso de la Biblioteca Episcopal de Mallorca. En ella se depositaron los libros duplicados procedentes de los Colegios de San Ignacio de Pollensa y de San Martín de Palma y constitu-

49 Libro II, Título XIII, Ley V.

50 Por Real Provisión de 12 de febrero de 1772 se determina que el empleo de bibliotecario habrá "de ser incompatible con cualquier Dignidad, Canonjía o Beneficio residencial, en horas incompatibles, o que distraiga al Bibliotecario de cumplir con su cargo", no debiendo recaer "en sujeto que sea Subcolector de espolios y vacantes, Provisor y Visitador, Secretario de Cámara, Notario de la Curia Eclesiástica, ni que tenga otra cualquiera Judicatura y O ficio, para escusar el perjuicio de que sirven mal uno y otro encargo". Nos encontramos, pues, ante una exigencia de dedicación específica. Cit. por Viñao Frago, A. El Colegio-Seminario de San Fulgencio: Ilustración, Liberalismo e Inquisición. Separata de Aras 6, 1986, p.23. 
yeron la base de la Biblioteca Episcopal. Parece que los volúmenes triplicados fueron vendidos en pública almoneda. 51

\section{B ibliotecas de los Seminarios}

Los seminarios serán objeto, como otros centros de enseñanza, de la acción reformadora de los políticos del siglo XVIII. Siguiendo los acuerdos del Concilio de Trento, los monarcas españoles acometerán las reformas y erección de nuevos seminarios para la educación del clero, en cumplimiento de la Real Cédula de 14 de agosto de 1768. Por ella, se manda erigir Seminarios Conciliares, donde no los hubiere, destinados a la educación del clero, al tiempo que se ordena ubicarlos en los edificios que habían quedado vacantes por el extrañamiento de los Regulares.

Nuevamente las temporalidades de la Compañía de Jesús van a ser utilizadas directamente en la constitución de nuevos o reformados centros de enseñanza, en este caso, eclesiales. Efectivamente, en los edificios expoliados será ubicada una serie de seminarios y, del mismo modo, una parte importante del patrimonio bibliográfico de los jesuitas será destinada a sus bibliotecas.

D e manera específica, la Instrucción de 2 de mayo de 1772, como ya veíamos señala que: "Habiendose destinado la Fábrica del Colegio de Tdeebpara el establecimiento de un Seminario, segun la mente del Concilio de Trento que ha de ser igualmente Clerical, y de Correccion, se reserva la Librería de aquel Colegio para uso de sus Directores, Alumnos, é Individuos." 52

El estudio de Eguía Ruiz, tantas veces mencionado, recoge noticias de más de veinte seminarios que de manera más o menos generosa disfrutaron en su momento de los libros de los expulsos. De la riqueza de algunas de estas colecciones nos queda constancia gracias a los catálogos conservados. ${ }^{53} 0$ tras veces, la presencia de leyendas 0 cartelas manuscritas nos aclaran la procedencia de los mismos.

51 C. Eguía Ruiz. Opait, p.249-250.

52 Cdeeción General delas providenias tomadas sdared etrañamiento y oupacón deTemparalidades de Reyr lares dela extinguida orden dela Compañía queexîstian en los Dominios deS.M. Parte Q uarta. Madrid: Imprenta Real de la Gazeta, 1774, p.43.

53 "En Zaragzase aprovechó el vaciado colegio jesuítico para Seminario sacerdotal, y así subsiste al presente con el nombre de San Carlos. Su erección data de 1788. Calcúlense las visicitudes que corrieron desde 1767 los libros de aquel colegio. De ellos pudieron pasar algunos a la Universidad. Pero sin duda la mayor parte pararon en aquel establecimiento eclesiástico, así como una riqueza grande de manuscritos que con otros muchos de varia extracción allí se conservan. La importancia de los libros heredados, aun supuesta la pérdida o malversación de muchas obras, puede deducirse fácilmente por el copioso y rico catálogo que conocemos”. Bdeín de Ardivos(3áépoca), t.19, p.417; t.20, p.117 y ss., cit. por Eguía Ruiz,C., Opait, p.245-246. 


\section{Bibliotecas de las Sociedades Económicas}

La presencia constante de la tutela real en las actividades culturales resulta incuestionable al ser analizadas, por una institución, las características del panorama ilustrado español. Aunque de iniciativa privada, las Sociedades Económicas de Amigos del País encontraron en los poderes públicos un apoyo incondicional. La primera de ellas, la Sociedad Vascongada, fundada en Vergara en 1763 por el conde de Peñaflorida, será el punto de partida para la implantación de otras muchas que, en sus respectivas regiones, tratarán de favorecer el desenvolvimiento cultural, económico y científico de sus áreas de influencia.

Este eficaz instrumento en la mejora de la "agricultura, industria y oficios, ó artefactos", objetivos perseguidos por las sociedades, recibirá pronto el aliento del Estado Ilustrado. Los estatutos otorgados en 1775 a la Sociedad Económica de Madrid son buena prueba de ello.

A lo largo de sus dieciocho títulos, vemos cómo el legislador normaliza su funcionamiento, no olvidando incluir un aspecto importante de la nueva asociación: su biblioteca o librería como se la denomina en el capítulo a ella dedicado:

1 Se irán recogiendo los escritos económicos, y políticos para el uso de la Sociedad, los oficios, y agricultura, con especialidad los publicados, ó traducidos por autores E spañoles.

2 Los socios que publicaren escritos de este género, harán muy bien en dar un exemplar para la Librería de la Sociedad.

3 Quando no hubiere ocupacion con que llenar las sesiones, será útil la lectura de algunas de estas obras, y el conferir sobre su método, y sistema, tomando la palabra los que tubieren mayor instruccion en aquel género de escritos, y continuándola con utilidad los que pudieren añadir, sin que empiecen á hablar unos, hasta que hayan concluido los otros. $^{54}$

Las Sociedades Económicas llegaron a formar Bibliotecas bastante surtidas, ricas en materiales renovados y alejadas de los fondos tradicionales que hasta el momento habían configurado las bibliotecas españolas. ${ }^{55}$

54 Rẹl Cédula deS.M y Señores dd Conşo, en queseaprubban los etatutos dela Socielad ecońnica deamigos de Pais, con lo demás quese expreaa, á fin depromover la agiailtura, industria y oficios Madrid: Imprenta de Pedro Marín, 1775, p.11-12.

55 Una parte importante del fondo estaba constituida por libros franceses por lo que las sociedades sirvieron de "puente entre la cultura española y la nueva filosofía francesa, apurando al máximo la tolerancia gubernamental y burlando la celosa vigilancia de la Inquisición". Fuentes, Juan F. “Luces y sombras de la Ilustración española”. Rev. deEducaión nno extraordinario, 1988, p.17. 
Este tipo de fondos, a diferencia de los analizados anteriormente, parece que fueron de carácter privado, para uso de los socios y, tal vez, por esta razón no son mencionadas por el conde de Campomanes en el informe referido.56

En resumidas cuentas, el análisis de las medidas, normativas y directrices emanadas del Estado nos hablan claramente de un planteamiento bibliotecario, que pretende analizar una necesidad social percibida por la minoría dirigente. Se trataba, en definitiva, de poner al alcance de todos, los instrumentos esenciales que posibilitasen la consecución del ideal ilustrado.

D esgraciadamente, como en otros tantos aspectos, la utopía ilustrada, no consiguió hacerse realidad; los proyectos bibliotecarios, la reorganización de los ricos fondos bibliográficos y el funcionamiento de nuevos y reformados establecimientos librarios, fueron tímidos e insuficientes para lograr modificar el panorama bibliotecario de la centuria. Sus "Bibliotecas Públicas" carecieron de los medios económicos indispensables que garantizasen la presencia en tales instituciones de un personal especializado, convenientemente remunerado y en número suficiente. Junto a ello, la renovación y actualización de sus fondos, siempre escasa, no pudo ser paliada con el expolio jesuítico. Si con esta acción las bibliotecas "públicas" incrementaron de hecho los volúmenes de sus anaqueles, estos contuvieron en su mayor parte volúmenes tradicionales y humanísticos y en una menor proporción textos científicos modernos y renovados.

Sin embargo, todas estas medidas ilustradas aportaron un aspecto enormemente positivo al panorama bibliotecario español. Por primera vez se esboza un intento estructural de organización bibliotecaria, al tiempo que se plantea de manera sistemática la tan necesaria conservación, incremento y uso de un patrimonio bibliográfico y documental de extraordinaria riqueza.

\section{Anexos}

\section{ANEXO I}

D .Felipe V, en Madrid por dec. de 2 de Enero de 1716.

Estableimientodela Rẹl Biblicteca óLibreía pública deMadrid.

Habiendo resuelto establecer una Biblioteca, y colocarla dentro de mi Real palacio de Madrid, se ha juntado en ella el mayor número de libros que hasta ahora se ha podido, con algunos manuscritos, varios instrumentos Matemáticos, porcion

56 Si están recogidas, por el contrario, las bibliotecas de las Reales Academias, tan necesarias para el ejercicio de las tareas a ellas encomendadas. Entre todas ellas, destaca la de la Academia de la Historia, siendo "numerosa y extensiva no sólo a la parte histórica, sino también a la cronología, G eografía y Antigüedades", Notica abreviada delas biblidecas..., Opcit., cap. IV y V. 
de monedas y otras curiosidades; para cuya subsistencia y manutencion la he dotado con ocho mil pesos de renta á el año, asignándoles en las del tabaco y naypes del Reyno, con la independencia y precision, para la puntual paga de ellos, que se ha juzgado conveniente: y haciéndose preciso asignar el número de Oficiales que ha de haber en la referida Librería, sueldos que estos han de gozar, y constituciones y establecimientos que se han de observar en ella; he resuelto, haya un Director general de la referida Librería, que ha de ser mi Confesor, y el que lo fuere en adelante; y debaxo de las órdenes de éste y á su dispocision ha de haber los ministros y oficiales siguientes: un Bibliotecario mayor con mil pesos escudos de salario á el año; quatro Bibliotecarios con quinientos pesos escudos de salario cada uno; un Administrador con otros quinientos pesos de salario á el año; dos escribientes con el salario cada uno de doscientos cincuenta pesos; un portero con doscientos pesos; y un ayuda con ciento. Y siendo la renta que, como queda dicho, se asigna á esta Librería de ocho mil pesos al año, é importando los sueldos aquí expresados quatro mil y trescientos; declaro, que los tres mil y setecientos restantes se han de emplear todos los años en la compra de libros que no hubiere, y en los demas gastos ordinarios y precisos de ella. Y habiéndose formado por mi Confesor las constituciones para esta Librería, he venido y vengo en aprobarlas, y mandar, como mando, se observen y cumplan, así por el Bibliotecario mayor actual, como por los otros Bibliotecarios y demas oficiales de esta Librería que actualmente hay en ella, y por los que hubiere en adelante, sin variar ni alterar las referidas constituciones con motivo alguno sin expresa órden mia: declarando tambien, como declaro, que todas las dependencias de la referida Librería ahora y en adelante han de correr y se han de despachar, con independencia de qualquier Tribunal y Ministro, por mano de mi Secretario del D espacho universal que corriere con el negociado de Casas Reales.

CONSTITUCIONES DE LA REAL Libreria de el Rey Nuestro Señor Phelipe Quinto.

I. El Confessor de el Rey será siempre el Director de la Real Libreria, para dar cuenta à su Magestad de lo que se executa en ella; y representarle lo que fuere necessario, para su estabilidad, y permanencia.

II. El Bibliothecario Mayor, dentro de la Libreria, será el Superior de los demás Bibliothecarios, y demás Ministros; y como tal mandará à todos en orden à lo conveniente à ella, y todos le obedecerán, como tal Superior.

III. El Bibliothecario Mayor dará noticia à el Director de los desordenes, que sucedieren en la Libreria, ò no pudiere emmendar, para que los ponga en la noticia de su Magestad, y dé providencia para el remedio.

IV. El Bibliothecario Mayor podrá dár licencia à los Bibliothecarios, y demás Ministros, para faltar à la Libreria por el tiempo de un mes, si tuvieren justa causa; y si fuere necessario mas tiempo, será esto proprio de el Director.

V. El Bibliothecario Mayor señalará à cada uno de los Bibliothecarios cada año, la parte de la Libreria, de que han de cuidar, y à demás señalará à cada uno la 
parte de lo recondito de la Libreria, como los manuscriptos, Instrumentos Mathemáticos, monedas, y medallas, y demás curiosidades.

VI. El Bibliothecario Mayor señalará à cada uno de los Bibliothecarios, y demás O ficiales, los quartos para su habitacion.

VII. Los quatro Bibliothecarios, los dos Escrivientes, y Porteros, han de assistir todos los dias à la Libreria, por la mañana, y tarde, excepto los dias de Fiesta, y los dias de la Semana Santa, y los dos dias de Feria en la O ctava de la Natividad de el Señor, por la santidad de los Misterios, que celebra entonces la Iglesia; y entrarán todos por la mañana, desde primero de Mayo, hasta fin de Septiembre, à las ocho, hasta las once; y por la tarde, desde las quatro, hasta las siete. Y deste primero de 0 ctubre, hasta fin de Abril, entrarán por la mañana à las nueve, hasta las doze; y por la tarde, desde las tres, hasta las seis; y en los meses menores, hasta las Ave Marias.

VIII. El Bibliothecario Mayor assistirá todos los dias à la Libreria (si no tubiere algun legitimo embarazo) el tiempo que fuere necessario, para que la Libreria esté en el debido, y conveniente estado, conforme à la confiança, que haze de él su Magestad; y si tubiere necesidad de ausentarse por algun tiempo, ha de ser con licencia de el Director; y si estubiere enfermo, ò ausente, cometerá sus vezes à el Bibliothecario, que le pareciere.

IX . Los quatro Bibliothecarios tendrán gran cuidado, de que los Libros estén limpios, haziendo, que los sacudan los Porteros, ò Escrivientes, y en su debido lugar, conforme à la parte, que à cada uno le tocare, y el Indice, que de ella tubiere.

X. Quando algun Bibliothecario estubiere enfermo, ausente, ò legitimamente ocupado, los dos mas inmediatos cuidarán de la porcion de la Libreria, que à el tal le tocare.

XI. Ninguno de los O ficiales de la Real Libreria, podrá sacár, ni extraer de ella Libro alguno, sin licencia, por escrito, de su Magestad; ni esto sea licito à el Director sin ella. Y si su Magestad se sirviere de darla, se tome recibo de la persona, para quien se diere la licencia, annotando el dia, mes y año, y se guarde el recibo, para cobrar el Libro, ò Libros, que se extrageren, passado el tiempo de la licencia, y se annote en el Libro, que ha de haver para esto.

XII. Los quatro Bibliothecarios han de sacár à los que vinieren à la Libreria los Libros, que pidieren, de su lugar, y voverlos à él; sin permitir esto à los que entraren de fuera à leer en la Libreria.

XIII. El Bibliothecario Mayor cuidará de los libros, que se necesitaren comprar para la Libreria, y dará el orden para vender, ò trocar los libros duplicados, que barriere en ella; señalando uno de los quatro Bibliothecarios para esto: el cual no pueda executar venta, cambio, ò trueque, sin el consentimiento de el Bibliothecario Mayor.

XIV. Q uando se compraren nuevos Libros, el Bibliothecario Mayor hará, que se escrivan en los Indices, y Cathalogos de ellos; y hará, que en dichos Libros los 
Escrivientes pongan la nota, ò el numero, que les conviniere, y se colocarán en el lugar correspondiente.

XV. El Administrador de la Libreria debe cobrar los efectos señalados por su Magestad, para la manutencion de ella, y sus Ministros, y satisfacerles sus sueldos con puntualidad, conforme à el orden de su Magestad; y cada año debe dár cuenta de la administració à el Bibliotheceario Mayor, con la assistencia de dos Bibliothecarios, que señalare el Mayor. Y ajustada la cuenta, el Bibliothecario Mayor la ponga en manos de el Director, para que la reconozca, y reconocida se guarde en la Libreria, para que conste de el caudal de ella.

XVI. El Administrador ha de tener obligación de comprar todo lo necessario para la Libreria; y dar tambien lo que fuere preciso para los gastos mayores, y menores de ella: para todo lo qual ha de tener libramiento, y orden el de el Bibliothecario Mayor, por escrito; y sin el, no se le passe en cuenta ningun gasto, excepto la paga de los sueldos de los Ministros, y O ficiales de la Libreria, que estos se le abonarán con solos sus recibos.

XVII. Los Escrivientes, en orden à su ministerio, executarán las ordenes, que les diere el Bibliothecario Mayor.

XVIII. El Portero, y su Ayudante, tendràn obligacion à abrir por la mañana la Libreria, à las horas señaladas; tenerla limpia, y asseada; y de la misma suerte por la tarde: y antes de cerrar las puertas de la Libreria, la reconocerán toda, para que nadie quede escondido en ella: y de parte de noche, despues de haverla cerrado, llevaràn las llaves à el Bibliothecario Mayor, ò à uno de los quatro Bibliothecarios, que han de tener este cuidado cada uno tres meses en el año. Y cerrada la Libreria de parte de noche, sin licencia de su Magestad no se pueda abrir, ni entrar con luz en ella. Y por parte de mañana vayan los Porteros à recibir las llaves de el Bibliothecario, para abrirla à las horas señaladas; y el Bibliothecario Mayor podrà solamente dar licencia, para que en algun caso se abra, por la mañana, antes de dicho tiempo.

XIX. Como su Magestad es el dueño de la Libreria, solo èl puede dàr, ò quitar las Plazas de ella; mas quando llegare à vacar alguna de ellas, el Bibliothecario Mayor avisarà de la vacante à el Director: el qual, despues de haver conferido con el Bibliothecario Mayor los sugetos convenientes para ella, los propondrà à su Magestad para su eleccion. Y si vacare la plaza de Bibliothecario Mayor, el mas antiguo darà esta noticia à el Director, para que su Magestad la provea; y en el interin, el Bibliothecario mas antiguo harà los oficios de Bibliothecario Mayor.

$\mathrm{XX}$. Todos los años se emplearàn en comprar Libros dos mil y quinientos pesos y quedaràn mil y doscientos para los gastos ordinarios de la Libreria. Y si despues de algunos años, no hubiere Libros en que emplear toda la cantidad de los dichos dos mil y quinientos pesos, la que sobrare se reponga en una arca de tres llaves, que la una ha de tener el Bibliothecario Mayor; la otra el Bibliothecario mas antiguo; y la otra el Administrador: y despues de tres años se ha de dàr 
cuenta de el caudal, que hubiere, à el Director, para que lo ponga en noticia de su Magestad, para su disposicion.

Guillermo D aubenton

\section{ANEXO II \\ D .Carlos III en Buen Retiro por céd. de 11 de Diciembre de 1761. Observania delas nuevas constituriones dela Real Biblictea estableida en Madid por la ley precedente}

Habiendo visto y exâminado con toda atencion las nuevas constituciones formadas por el Bibliotecario mayor de mi Real Biblioteca, fundada en mi Real Palacio por el Rey mi Señor y padre en su decreto de 2 de Enero de 1716; vengo en aprobarlas en todos sus capítulos, para que desde ahora en adelante se observen y guarden inviolablemente ::: previniendo, que los caudales de su dotacion y sueldos de sus individuos quiero se paguen por tercios por mi Tesorería general; $\mathrm{y}$ he mandado expedir á mi Mayordomo mayor el decreto correspondiente á la declaracion de criados de mi Real Casa á todos los individuos de la Biblioteca.

1. La Biblioteca, como fundación Real, y una de las mas preciosas alhajas de la Corona, de que resulta tanto beneficio y honor al Estado, estará siempre baxo la proteccion de S. M.; y todas sus dependencias y negocios correrán siempre privativamente, con entera independencia de otro qualquier Ministro, por el Secretario del D espacho universal que tuviere á su cargo las Casas Reales.

2. D e todas las obras, libros, papeles y escritos de qualesquiera clase, y por pequeños que sean, que se impriman ó reimpriman en los Reynos y dominios de S.M., se deberá entregar un exemplar á la Real Biblioteca, en conformidad del Real decreto de 26 de Julio de 1716...: y á fin de que cesen las dudas, que algunos han suscitado voluntariamente para excusarse de la entrega del exemplar de cada libro ú obra; se declara ser comprehendida en dicha obligacion no solo las obras de primera impresion, sino todas las reimpresiones que se hicieren de ellas, aunque sean identicas, y por los mismos autores ó sugetos que hubieren hecho, costeado o corrido con las primeras; todos los quales, y qualesquiera otros que sean dueños de la impresion ó reimpresion, ó la costeen, ó corran con ella, han de tener la expresada obligacion. Y para su debido efecto y cumplimiento, y cortar los embarazos que hasta ahora lo han impedido, deberán siempre todos los impresores reservar en su poder un exemplar de qualquiera obra, libro, mapa ó papel que impriman, y enviarle á la Real Biblioteca; sin cuyo recibo no pasarán á entregar la obra ó libro á su autor, ó al dueño de la impresion, ni se podrá poner en gazeta, venderse ni hacerse uso alguno de ella.

3. Siendo muy conveniente que en la Real Biblioteca se conserven todas las ordenanzas, reglamentos, pragmáticas, cédulas, decretos y demás papeles que de 
órden de S.M. se imprimieren por las Secretarías del D espacho universal, Consejos y Tribunales de estos Reynos; y habiéndose comunicado esta resolucion que ha tomado S.M., para que los impresores respectivos no puedan excusarse con pretexto alguno de su cumplimiento, tendrán estos la misma igual obligacion de reservar y remitir á la Real Biblioteca un exemplar de cada ordenanza, reglamento, pragmática, cédula, decreto ó providencia respectiva que hubieren impreso; y deberán acompañar el correspondiente recibo de la Biblioteca, quando presentaren á las Secretarías, Consejos etc. las cuentas de las impresiones que hubieren hecho de su órden.

4. En conseqüencia del privilegio que goza la Real Biblioteca, para que todos los tasadores de librerías, que quedan de venta por muerte de sus dueños, ó por otros motivos, la den puntual noticia de la tasacion que hubiesen hecho, para que pueda tratar de su compra..., tendrán los expresados tasadores precisa obligacion de pasar aviso al Bibliotecario mayor de todas las que se tasasen, con copia firmada de su mano, que comprehenda los libros impresos y manuscritos de cada una; previniendo á los dueños, ó sugetos que las tuvieren á su cargo, no pasen á efectuar su venta en el término de quince dias siguientes, para que dentro de él pueda resolver el Bibliotecario mayor, si conviene ó no comprarlas para la Real Biblioteca; lo que podrá executar ajustándose con los dueños, ó sugetos que deban venderlas, ó bien por el tanto que ofrecieren otros compradores, de que se le deberá dar aviso formal, como tambien del dia en que se abriese su venta por menor, quando no resuelvan hacerla del modo expresado.

5. Para los gastos precisos anuales que debe hacer la Real Biblioteca, así para su conservacion como para el servicio del Público, tendrá en cada un año treinta y nueve mil trescientos cincuenta y seis reales de vellon, que es lo que importan todos, computados á cada clase; y se incluirán en las cuentas del Tesoro como hasta ahora.

6. A simismo tendrá otros cincuenta mil reales de vellon para compras ordinarias de libros impresos y manuscritos, medallas é impresiones, en esta forma: veinte mil para libros para libros impresos y manuscritos, diez mil para medallas y antigüedades, y veinte mil para impresiones; y se incluirán en la misma cuenta del Tesorero, ó bien se llevará otra anual separada para darla á S.M., como se dispone en el cap.15.núm.6 de estas constituciones.

7. La Real Biblioteca tendrá para su custodia y quietud el Cuerpo de guardia que hoy tiene, ó bien el que S.M. destinare en adelante, siempre á las órdenes del Bibliotecario mayor en lo perteneciente á la Biblioteca: y conforme á ellas podrá registrar á los que entraren á salieren de ella, no dexando sacar libro alguno; y si hubiere quien lo intentare, le detendrá, y dará cuenta al Bibliotecario mayor, ó á alguno de los quatro Bibliotecarios. Tampoco permitirá, que se entre en ella con gorro, cofia, pelo atado, embozo ú otro trage indecente ó sospechoso, ni muger alguna en dias y horas de estudio; pues para ver la Biblioteca, podrá ir en los feriados con permiso del Bibliotecario mayor. D e noche tendrá abierta la puerta de 
la calle, y luz en el zaguan en invierno y verano; asistiendo allí, y rondando, á la hora que señalare el Bibliotecario mayor, la circunferencia y territorio de la Biblioteca, para precaver riesgos de incendio, y otros que puedan sobrevenir: y en todo lo demas que se ofrezca conducente á estos fines, estará el expresado Cuerpo de guardia á las órdenes que le diere el Bibliotecario mayor por sí ó por medio de los Bibliotecarios. 57

\section{ANEXO III \\ REAL CEDULA, COMPREHENSIVA DE LA INSTRUCCION deloquese deberá doservar, para inventaniar los Libros y Papdes exîstentes en las Casas quehan sidbdelos Regulares dela Compañía en todos los Daminios deS.M.}

D on Carlos, por la gracia de Dios, Rey de Castilla... A vos los Jueces Comisionados, que por especial delegacion del Conde de Aranda, Presidente de nuestro Consejo, entendeis en estos D ominios de España, y en los de las Indias, Islas Filipinas, y demas adjacentes, en las diligencias respectivas á el estrañamiento, y ocupacion de temporalidades de los Regulares de la Compañía, en cumplimiento del Real decreto, expedido por nuestra Real Persona, en veinte y siete de Febrero prôximo pasado, á consulta de nuestro Consejo Real de veinte y nueve de Enero antecedente, en el Extraordinario que se celebra con motivo de las occurrencias pasadas, salud y gracia. SABED, que en veinte y dos de este mes por nuestro Fiscal, D. Pedro Rodriguez Campománes, se presentó pedimento, exponiendo que en su antecedente de cinco del mismo, sobre que recayó nuestra Carta de siete de él, que se os há comunicado, se reservó proponer al nuestro Consejo el método individual de formalizar el Indice, y reconocimiento de Libros, y Papeles de las Casas de la Compañía, por requerir reglas especiales, para que se executase con uniformidad en todas ellas, y con el debido método, distincion, y claridad; porque no haciéndose así se caería en confusion, y mucho mas si se entregase esta diligencia al cuidado de los Escribanos, agenos por lo comun de literatura, y del idioma Latino, y demas lenguas en que se hallan los mejores Libros; y que por otro lado reduciendose á un Inventario en papel sellado, autorizado de Escribano, sería una obra cansada, y prolija, que consumiría muchos salarios y costas, y absorveria en algunas partes el valor de los Libros: llegándose á esto, que el método de ordenar los papeles no es dado á otras personas, que á las versadas en

57 En los demás capítulos hasta el 16, que contienen estas constituciones, se trata de los individuos de la Real Biblioteca, sus calidades, y sueldos: del Bibliotecario mayor; de los Bibliotecarios; del Tesorero; Administrador; de los oficiales escribientes; de los porteros; de los índices, catálogos é inventarios; de los libros de cuenta y razon; del archivo; de las arcas y caudales; de las puertas y llaves; de la asistencia y dias feriados; del cuidado y custodia de la Real Biblioteca; de las Juntas y de los sellos. 
negocios, y literatura, y como no son frequentes, habia conceptuado el nuestro Fiscal por indispensable reducir todo esto á reglas, y clases, con las advertencias, y precauciones convenientes, á cuyo efecto habia dispuesto la Instruccion rubricada, que presentó en veinte y quatro Artículos, y pidió que, con su insercion, se comunicase á todos los D elegados, y Executores, para que arreglándose á ella en esta parte, se adelantase un ramo tan esencial de los Inventarios, y diligencias pendientes en las Casas, que fueron de los Regulares de la Compañía del nombre de Jesus, precediendo nuestra aprobacion, baxo de las adiciones, y declaraciones que tubiésemos por conveniente; y con dicho pedimento, en efecto, presentó nuestro Fiscal la Instruccion, que consta de los referidos veinte y quatro Capítulos, la qual dice así:

\section{INSTRUCCION DE LOQUE SE DEBERA OBSERVAR, PARA INVENTARIAR LOSLIBROS, Y PAPELESEXISTENTESEN LASCASAS, QUE HAN SIDO DE LOSREGULARESDE LA COMPAÑIA, EN TODOS LOS DOMINIOS DE SU MAGESTAD.}

I Primeramente los Libros se dividen en impresos y manuscritos y de cada clase se hará Indiceseparado, expresado el tamaño de marca mayor, folio, quarto, ú octavo.

II Se colocarán por órden alfabético los apdlidos de los Autores, poniendo seguidamente entre paréntesis el nombrepropio, y todo el título ó portada, para que se venga en conocimiento del contenido de la obra.

III En los impresos se pondrá también el lugar, y año de la eidion, porque esto contribuye á saber si es la primera, ó si es reimpresion: lo qual conduce mucho en especial respecto á los Libros de Moral, en que há habido algunas variaciones sucesivas.

IV En los manuscritos se pondrán los dos primeros renglones con que empieza la obra, y los dos últimos con que finaliza, y el número de folios de que consta; consiguiéndose por este medio saber si el manuscrito está íntegro, ó diminuto.

V Si hubiere algunos Códices merbranácess, en letra gótica, ó monacal antigua, se colocará entre los manuscritos, expresando en efecto si se hallan escritos en vitela.

VI Suele acontecer que en un mismo vdúmense hallan diferenttes obras encuadernadas unidamente, y será del caso ojearlas al tiempo de hacer el Indice, para advertirlo; y en este caso se pondrá en cada una el principio, y fin, en la forma que yá queda prevenido en el artículo iv.

VII Aunque sean Libros de Sermones, Cursos de Artes, materias de Theología, O raciones retóricas, Relaciones históricas, y otras semejantes, Q uadernos, Relaciones de Fiestas, Conclusionnes, y otros semejantes, se colocarán en el respectivo Indice de impresos, ó manuscritos, poniéndoles el número, para que con él correspondan al Indice, y se hallen con facilidad. 
VIII Los Libros, y Papeles que se hallen en los Aposentos, se reconocerán uno por uno, y se harán Inventarios particulares, para trasladarlos luego al Indice general.

IX Conforme se vaya evacuando cada aposento, se irán trasladando los Libros yá impresos, yá manuscritos, á la Libreía si es capaz; y en su defecto á otra pieza suficiente, para que se hallen baxo de una llave, y se les dé el destino que corresponda.

X Los demás Papeles manuscritos se reducen á instrumentos públicos, libros de cuenta y razon, vales, y cartas de correspondencia.

XI D e cada clase de estas se hán de hacer legajos separados, sin omitir papel alguno por inútil y despreciable que parezca; pues todos se deben recoger, y ordenar con el mayor cuidado.

XII Las cartas se pueden reducir á tres clases, que son: correspondencia de intereses pecuniarios, correspondencia literaria, y correspondencia privada, en que se traten asuntos acaso de gobierno; y baxo de estas tres clases se deben hacer legajos con su carpeta y cinta, expresando en la rotulata el Padre, y aposento á que pertenecen.

XIII Se colocarán las cartas de cada legajo por antig̈̈edad defechas, y es de esa manera fácil su inteligencia, porque la série cronológica de los tiempos conduce á ella con facilidad, y órden.

XIV Aunque sean poesías, papeles satíricos, y de otro qualquiera especie, no se despreciarán, ántes se procurará colocarlos con cubierta separada.

XV La misma se pondrá á las Escrituras de fundacion, títulos de pertenencia, Congregaciones, ó fundaciones pías, para que de todo haya noticia.

XVI La formacion de Indies de Libros impresos, donde hubiere Libreos hábiles, se podrá encomendar á estos, y que al mismo tiempo hagan su tasacion, cuidando algun literato inteligente, é imparcial, rever la ortografía, y exâtitud de los Indices.

XVII En quanto á los manuscritos deben aun ser de mayor satisfaccion los que se encarguen de su reconocimiento, y formacion de Indice, por la importancia de que no se extravien; y no será preciso poner en Inventario judicial estos Indices, contentándose el Juez Executor con colocar firmado el Indice en Autos, y poner diligencia de estar conforme con el númmero de volúmenes exîstentes en la Biblioteca comun, y aposentos de la respectiva Casa.

XVIII Suele acontecer, que en granjas, ó residencias anexas á los Colegios, hay Papeles y Libros manuales, que servian al uso de los Regulares, que por tiempo residian en ellas; y, como pertenecientes á la Compañía, deben añadirse al Indice de Libros de la respectiva Casa, baxo de las reglas que ván indicadas respecto á los aposentos, por militar iguales circunstancias.

XIX A las Pateias se vendian Obrasimpresas de estos Regulares, por cuenta de sus Comunidades, de las quales se debe hacer Inventario, con expresion de los exemplares en papel, ó encuadernados, que se encontraren, y el precio á que se 
vendia cada tomo, ó juego, para darles salida, como caudal, y efectos de la misma Casa.

XX Por la misma razon, si alguna de estas O bras se vendian por Impresores, Libreros, ó otras personas eclesiásticas, ó seculares, se ajustará la cuenta con ellas, así del producto, como de los enseres, abonandolos la comision.

XXI Es regular tambien se encuentren Impretas de las Comunidades, en confianza á nombre de Seglares, y de ellas se hará Inventario formal, con distinción de Prensas, Fundiciones de Letra; Caxas, Papel, y demás peltrechos; para ponerlas en debido cóbro, y proporcionar su venta á Seculares, en quienes deben existir conforme á las órdenes circulares del Consejo, por ser este manejo impropio de Casas Religiosas, y perjudicial su exîstencia en los privilegiados.

XXII Ultimamente, si hubiese Obras que de cuenta de estas Comunidades, ó individuos de ellas, se estubiesen imprimiendo al tiempo de la novedad ocurrida con dichos Regulares, se sobreseerá en la impresion, inventariará su exîstencia, y recogerá el original por el Juez Executor, exâminando la licencia, y ajuste baxo de que se imprima, sobre que se tomará declaracion al Impresor, y siendo la obra corriente, y usual, se continuará; pero siendo nueva, ó añadida, se consultará al Consejo.

XXIII Los demás casos no prevenidos se gobernarán conforme al espíritu de esta Instruccion, y á lo que está dispuesto por derecho, consultándose en los casos dudosos y graves.

XXIV D onde quiera que hubiere Universidades podrá ser útil agregar á ellas los Libros que se hallaren en las Casas de la Compañía, situadas en los mismos Pueblos; y para poderlo decretar el Consejo con conocimiento, consultará el Executor, de acuerdo con los Diputadbs que nombre el Claustro, que será un graduado de cada Facultad. Madrid y Abril veinte y dos de mil setecientos sesenta y siete.

\section{ANEXO IV}

REAL PROV ISION DE LOS SEÑORES da Consjoene Extraardinanioá consulta con S.M, en queseinduyela Instruccion fomada sdored destimo detodas las Libreńas exîstentes enlas Casas, Cdeejos, yResidenias quelos Regulares dela extinguica Compañía dexaronen etos Dominios, conlas reglas quatunas para procederá su entreea, yctras preveniones quese han estimadb converientes.

D on Carlos por la gracia de Dios, Rey de Castilla, de Leon... A vos los Presidentes, é Individuos de las Juntas Provinciales y Municipales, creadas en estos Reynos para los asuntos respectivos á la ocupacion de Temporalidades de los $R e$ gulares expulsos de la Compañía llamada de Jesus y demás personas á quienes lo contenido en esta nuestra Carta toque, ó tocar pueda en qualquier manera, salud y gracia. SABED, que á Consulta de la Cámara de diez y siete de Diciembre de 
mil setecientos y sesenta, vino nuestra Real Persona en aprobar el Reglamento executado por Don Manud Ventura deFiguera, de nuestro Consejo y Cámara, Colector G eneral interino, que entonces era de Espolios y Vacantes, para el establecimiento de un fondo correspondiente á anticipar el gasto de Bulas de las cinquenta y seis Mitras de estos Reynos, y otras cosas dirigidas al mayor alivio de los Prelados á su ingreso en la Diocesis. Entre ellas se mandaron reservar perpetuamente á favor de las Mitras todas las Librerías, que se encontrasen á la muerte de los Prelados para el uso de sus sucesores y familia, y para el aprovechamiento público de sus D iocesanos, principalmente de aquellos que se dedican al estudio y la predicacion, y demás exercicios del pasto espiritual de las Almas; prescribiendo las mas oportunas reglas para el adelantamiento de estas Bibliotecas públicas, que se han de colocar en los Palacios Episcopales con los respectivos Bibliotecarios baxo la proteccion de la Cámara; aplicando nuestra Real Persona á estas Librerías públicas los libros, que no se hallasen destinados de los expulsos de la Compañía Habiendose dado aviso de esta Real resolucion en quatro de Enero de mil setecientos setenta y uno al Conde de Aranda, Presidente de nuestro Consejo, á fin de que haciendolo presente al Extraordinario dispusiese el cumplimiento en la parte que le tocaba en quanto á los referidos libros de los expulsos de la Compañía, que no se hallasen destinados: Pasado á nuestros Fiscales D. PeedroRo digræe Campanánes y D. Joæf Moñing con lo que expusieron consultó nuestro Consejo en el Extraordinario en veinte y siete de Agosto del mismo año lo que estimó conveniente en punto á que declarase nuestra Real Persona, que en la concesion hecha por punto general no se comprehendian los papeles manuscritos, y de pura disciplina interior, y exterior de los Regulares expulsos, y otros que se expresaban; contemplando util, que además de las Librerías que estubiesen aplicadas anteriormente, tambien se exceptuasen las de los Collegios de Lgda y Villagarcia, las de los Pueblos en que se hallan las Universidades aprobadas, y las de Palmay Tdøbexecutandose la entrega de las que restasen con arreglo á la Instruccion que se formase, y en que se comprehendiesen varios puntos propuestos por nuestros Fiscales, dandose las ordenes convenientes, y escribiendose á los Reverendos Prelados las Cartas acordadas que indicaron. Y habiendose nuestra Real Persona conformado en todo con el parecer de nuestro Consejo, por resolucion á dicha Consulta, publicada en veinte y nueve de 0 ctubre del mismo año, se mandó cumplir, y que para ello poniendose Certificacion en el Expediente á donde correspondía pasase á nuestros Fiscales. En su conseqüencia expusieron en respuesta de quince de Enero próxîmo lo que se les ofreció para la execucion de lo resuelto; y visto por el nuestro Consejo en el Extraordinario de cinco de Febrero siguiente, se mandó formar la Instruccion mencionada, que en efecto se hizo, y su tenor dice asi: 
INSTRUCCION QUE SE FORMA da arden di Consjoend Extraadinario, yddberá dbservarsepar las respetivas Juntas Proiniales, yMunicipales enla entreega delas Libreías, quequedarcn enlas varias Casas, Cdegjos, y Residanaas quelos Regulares dela Compañía etrañados tubieronen estos Regnos, aplicadas por S.M. á Consulta dela Cámara para Biblicteras públicas delos Palacios Episcopales, con las limitacionesy excepiones, queseha dignadbhacerá consulta de propio Consgoend Extraardinario, ydanásacordado par ésteen d asunta

I. Q uedan exceptuadas desde luego de esta gracia todas las Librerías, ó juegos de libros, que por providencias de S.M., ó del Consejo se hallen aplicadas antes de ahora; debiendose llevar á efecto, si ya no lo estubiese, lo resuelto sobre este particular.

II. Estando aplicados los Colegios de Loyda y Villagaráa para Seminarios de Misioneros, que pasen á la propagacion de la Fé en la Améica Meridional, la Septentrional y Filipinas y siendo indispensable proveerles de libros en suficiente número y calidad, no solo se exceptúan para este fin las Librerías de dichos dos Colegios, sinó que las Juntas Provinciales de Valladdid y Guipuzcoa deben atender á dichos Seminarios, aplicandoles los libros correspondientes de los que exîstan en los demás Colegios y Casas de la comprehension de ellas.

III. Tambien se reservan á beneficio de las Universidades del Reyno, aprobadas por las ultimas providencias, las Librerías de las Casas y Colegios que tenían los expulsos en los Pueblos donde exîsten, debiendo servir para la educacion de sus Estudiantes, y funciones literarias; sucediendo lo mismo respecto á las Librerías de los dos Colegios de Palma, las quales quedan á beneficio de aquella Universidad; pues aunque no es de las aprobadas, milita el poderoso motivo de ser la unica que hay en la Isla de Mallarca, que por sus circunstancias requiere este auxîlio.

IV. Habiendose destinado la Fábrica del Colegio de Tdebb para el establecimiento de un Seminario, segun la mente del Concilio de Trento que ha de ser igualmente Clerical, y de Correccion, se reserva la Librería de aquel Colegio para uso de sus Directores, Alumnos, é Individuos.

V. Hechas estas limitaciones se declara, que las demás Librerías de las Casas y Colegios de España están comprehendidas en la gracia de S.M. para Bibliotecas públicas de los Palacios Episcopales; con advertencia de que los papeles manuscritos, y de pura disciplina interior y exterior de los Regulares expulsos, y los demás que miren á su gobierno político, y materias que puedan conducir para los fines del Gobierno, é igualmente los que correspondan á la clase de títulos de pertenencias y derechos temporales, que competían á los expulsos, deberán reservarse y remitirse con la debida distincion y separacion de clases al Archivo de San Isidro \& Real de esta Corte, consiguiente á lo prevenido en la Circular de 2 de Mayo de 1769, para que el Director de los Estudios Reales, de acuerdo con los 
Bibliotecarios, y la Contaduría, en lo respectivo á derechos temporales, los hagan colocar con distincion de Colegios, á cuyo fin se les comunicará la orden correspondiente.

VI. En esta inteligencia, y con arreglo á lo que vá contenido en esta Instruccion, las Juntas Provinciales de los respectivos territorios dispondrán, que las Municipales de su mando pongan en execucion, con la brevedad mas posible, la entrega de Librerías á los Reverendos Arzobispos y Obispos, para que tenga efecto lo resuelto por S.M., á cuyo fin tratarán con los mismos Prelados, ó personas que deputen; executando lo mismo respecto á las que tienen distinta aplicacion con las Universidades, y demás personas á quienes corresponda, reservando las de Valladblidy Guipuzca los libros que se separen para los Seminarios de Misioneros de Indias, para que á su tiempo se entreguen á quienes corresponda.

VII. Unas y otras han de hacer las entregas de Librerías, recogiendo formal recibo, antecediendo el hacer reconocimiento de aquellos libros que contengan máximas, y doctrinas perjudiciales á el Dogma, Religion, buenas costumbres, y regalías de S.M. los quales han de quedar separados en las mismas Bibliotecas Episcopales, y en las de las Universidades y Seminarios, á quienes se aplican, á disposicion de S.M. y del Consejo para lo que pueda conducir á los objetos del Gobierno.

IX. Los libros de la Escuela llamada Jesútica, en quanto á la enseñanza, se han de reservar asimismo en las propias Librerías á donde se remitan, conforme á las Reales Cédulas expedidas por el Consejo. Madrid 27 de Abril de 1772. D. Peero Rodiguez Campanánes D. Josf Mañina

Y para que tenga efecto lo resuelto, fue acordado librar esta nuestra Carta para Vos; por la qual os mandamos, que arreglandoos en todo á lo contenido en la Instruccion inserta, procedais á executar quanto contiene, sin contravenir, ni permitir se conntravenga en manera alguna á lo que previene, antes sí lo lleveis á puntual efecto, por ser asi nuestra voluntad, y que el traslado impreso de esta nuestra Carta, firmado de D.Josf PayoSanz, nuestro Escribano de Cámara honorario del Consejo, con destino y exercicio en el Extraordinario, se le dé la misma fé y crédito que al original. Dada en Madrid á 2 de Mayo de 1772. El Condede Aranda. El Marqués de S. Juan deTasá D. BemardbCaballera D. Juan deLeún Braca monte D. PeedrodeAvila Yo D. Jose PayoSanz, Escribano de Cámara honorario del Consejo, la hice escribir por su mandado en el Extraordinario. Registrada. D. NicdásV eduga Teniente de Chanciller Mayor. D. NiclásV edugo 


\section{ANEXO V \\ D. Carlos IV en Aranjuez por céd. de 6 de Mayo de 1804 con insercion de las or- denanzas para los Colegios de Cirugía cap.12. \\ EstableimientodeBiblicteeas públicas en los Cdeejos deCinuǵa, yórden queseha dedbser- varenellas}

En cada uno de los Colegios de Cirugía ha de haber una oficina destinada para Biblioteca; en la qual se procurará tener todas las mejores obras de la Facultad y sus ramos auxîliares para la instruccion pública, haciéndose sucesivamente una colección de las que se consideren más convenientes á este fin: y el empleo de Bibliotecario recaerá en uno de los catedráticos supernumerarios; el qual, ú otro profesor del Colegio, le substituirá en los casos de enfermedad ó ausencia, para que no se falte al cumplimiento de las obligaciones de este destino.

2. D ebiendo ser pública esta Biblioteca, se permitirá la entrada en ella á toda persona decente, sea ó no de la profesion; y se la subministrarán los libros que pidiese: y para que los que asistan puedan leer con comodidad, y hacer los apuntes que tengan por convenientes, habrá los asientos necesarios, y mesas con recado de escribir. El Bibliotecario cuidará, que despues que hubieren concluido, le vuelvan á entregar los libros, que colocará inmediatamente en el estante á que correspondan, pues ninguno podrá sacarse de la Biblioteca.

3. Asistirá á ella el Bibliotecario, y estará abierta todos los dias del curso, menos los jueves y fiestas, de diez á doce de la mañana, y de tres á cinco de la tarde en los meses de O ctubre, Marzo y Abril; de diez á doce de la mañana, y de dos á quatro de la tarde en Noviembre, Diciembre, Enero y Febrero; y en Mayo y Junio de nueve á once por la mañana, y de quatro á seis por la tarde; y si por ocupacion ó impedimento legítimo no pudiese á alguna de estas horas permanecer en la Biblioteca, dexará en ella á uno de los discípulos de su mayor confianza y desempeño.

4. Seguirá correspondencias literarias, y hará de Secretario de Literatura del Colegio en todas las que éste entablare de dicha clase: formará y tendrá dos índices alfabéticos de los libros que hubiere en la Biblioteca, uno por apellido de los autores, y el otro por las materias de que traten, con expresion del número del estante donde esten colocados. Estos índices servirán al mismo tiempo de inventario de todas las obras que hubiere en la Biblioteca; y por él hará entrega de ellos el que saliere de este destino, y se hará cargo el que le suceda.

5. Ha de cuidar el Bibliotecario del buen órden y decoro de la Biblioteca, y de que los concurrentes á ella guarden la debida circunspeccion y silencio, para que no se interrumpan en la lectura; y podrá negar la entrada, ó hacer salir de la sala á los que no observaren estas reglas tan conformes á toda sociedad. 
6. Tambien será del cargo del Bibliotecario la adquisicion de todas las obras útiles Facultativas y de ramos auxîliares, que se publiquen dentro y fuera del Reyno, precediendo la aprobacion del Colegio, y de la Junta superior G ubernativa, y la venta de los que se hayan impreso de cuenta del Colegio y á su beneficio, cuidando de su enquadernacion. D el producto de estas presentará cuenta formal al fin de cada año, para que el Colegio incluya su importe por partida de cargo en la general que debe rendir y otra en que especifique el costo de los libros que hubiese comprado y puesto en la Biblioteca, y los gastos que para el mejor aseo y servidumbre de ésta, y por razon de correspondencia se hubieren originado, acompañando los recados justificativos, para que aprobada por el mismo Colegio, se inserte por partida de data en la expresada cuenta general.

\section{ANEXO VI}

D. Carlos III en el Pardo por resol. á cons. de 17 de Diciembre de 1770, y cédula de la Cámara de 17 de Febrero de 1771.

Estableimientodeun fondopara costear la expedicion debulas delos Arzdaisposy Obispos: reseva dealhajas para e usodelos Prdadbs, ydelibros para biblidtecas púdicas

He venido en mandar expedir la presente cédula para la puntual observancia y cumplimiento del siguiente reglamento, que debe observar la Colecturía general y demás á quienes toque.

\section{REGLAMENTO}

28. Resérvanse asimismo desde ahora en adelante perpetuamente á favor de las Mitras todas las librerías de los Prelados, que se encontrasen al tiempo de su muerte, para el uso de sus sucesores y familia, y para el aprovechamiento público de sus diocesanos, principalmente de aquellos que se dedican al estudio de la predicacion, y demas exercicios del pasto espiritual de las almas.

29. A la muerte del Prelado formará el Subcolector un índice de los libros que dexase, con expresion de sus autores, materia de la obra, y lugar de su impresion.

30. El Colector general, con vista de este índice ó inventario, ha de destinar del respectivo espolio y vacante aquella parte que permitan las necesidades de la diocesis, para que emplee en algunos libros importantes y útiles á este establecimiento: en inteligencia de que tengo mandado aplicar á estas librerías públicas los libros, que no se hallan destinados, de los expulsos de la Compañía.

31. Por la notoria utilidad que resulta a las Mitras y sus diocesanos, se declara también por necesario en cada diócesis un empleo de Bibliotecario, con la 
obligación de responder de los libros que se les entreguen, y asistir en la librería ó biblioteca tres horas por la mañana y dos por la tarde, todos los dias que no sean festivos.

32. Los Prelados por medio de mi Consejo de la Cámara me propondrá tres Eclesiásticos diocesanos de buena literatura y exemplo, para que yo nombre al que sea de mi Real agrado.

33. El Bibliotecario, ántes de entrar á servir este empleo, ha de hacer formal obligación á favor de la Mitra de respoder de todos los libros que se les entreguen; y de asistir en la biblioteca tres horas por la mañana y dos por la tarde, como queda expresado.

34. Por razon de su trabajo se le han de asignar de los frutos de la Mitra de quatrocientos á ochocientos ducados, segun el prudente arbitrio del Prelado con presencia de todas las circunstancias; los quales les satisfará en Sede plena, y en Sede vacante lo hará el Colector general de los frutos de ella, como se executa con los demas oficiales de la Mitra, no siendo el Bibliotecario ménos útil y necesario que estos.

35. Se me harán presentes estas asignaciones de los Bibliotecarios, para tenerlas en consideracion al tiempo que se cargan las pensiones de las Mitras.

36. Se ha de encargar á los Bibliotecarios, se dediquen eficazmente por su parte, para que se verifiquen los adelantamientos que deben esperarse de esta providencia, que dispensa á mis vasallos mi amor y piedad; con la seguridad de que mi Consejo de la Cámara atenderá particularmente á los que se distingan, y me hará presentes sus méritos.

37. Los Prelados señalarán en sus palacios episcopales aquellas piezas que consideren mas á propósito para colocacion de la biblioteca, y concurrencia de sus diocesanos; estableciendo las conferencias y estudios que consideren mas útiles y convenientes, sin perjuicio de las Universidades donde las hubiese.

38. Tendrán presentes los mismos Prelados á los que se señalen en su aplicacion y aprovechamiento, para favorecerles y colocarlos; dando tambien cuenta de sus méritos á mi Consejo de la Cámara, para que se les atienda en las provisiones Reales.

39. Estas Bibliotecas han de estar baxo la proteccion de mi Consejo de la Cámara, con quien deben entenderse los Prelados; siendo comprehendidos en este reglamento, no solo los Arzobispados y Obispados que vacaren en lo futuro, sino tambien los que han vacado desde el dia 27 de Noviembre de 1768, en que se publicó en mi Consejo de la Cámara la resolucion mia á su consulta.

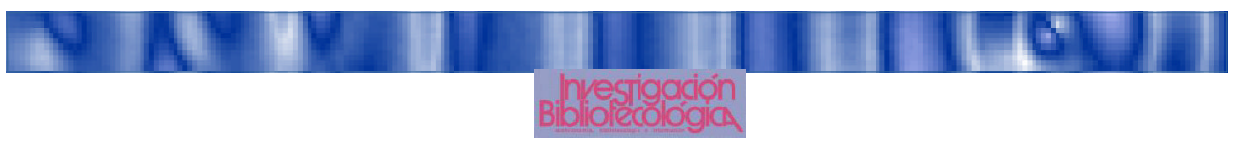

